\title{
International Family Planning Fellowship Program: Advanced Training in Family Planning to Reduce Unsafe Abortion
}

By Vanessa $K$. Dalton, Xiao Xu, Patricia Mullan, Kwabena A. Danso, Yao Kwawukume, Kofi Gyan and Timothy R.B. Johnson

Vanessa K. Dalton is associate professor,

Kofi Gyan is project coordinator, and

Timothy R.B. Johnson is professor, Department of Obstetrics and Gynecology, and Patricia Mullan is professor, Department of Medical Educationall at the University of Michigan Medical School, Ann Arbor,

MI, USA. Xiao Xu is assistant professor, Department of Obstetrics and Gynecology,

Yale University, New Haven, CT, USA.

Kwabena A. Danso

is professor, Depart-

ment of Obstetrics and

Gynecology, Kwame Nkrumah University of

Science and Technology

School of Medical Sci-

ences, Kumasi, Ghana.

Yao Kwawukume is

professor, Department of Obstetrics and

Gynecology, University of Ghana, Accra.
Maternal mortality remains a huge problem in the developing world, especially in Sub-Saharan Africa. ${ }^{1}$ According to the World Health Organization, efforts intended to decrease maternal deaths need to recognize and address unsafe abortions as a significant contributor to the high rates of maternal mortality found in developing countries. ${ }^{2,3}$ In Africa, where abortions are highly restricted, 680 women die per 100,000 abortions, compared with 0.2-1.2 women per 100,000 in developed countries, where most abortions are legal. $^{4}$

Ghana has one of the most liberal abortion laws in the region. Nevertheless, an estimated two-thirds of abortions in Ghana are still obtained illegally under unsafe conditions, suggesting that the legalization of abortion is not sufficient to substantially decrease the occurrence of unsafe abortion. $^{5-7}$ One study estimated that there are 27 abortions for every 100 live births, ${ }^{8}$ and most of these are believed to occur under unsafe conditions. Abortion-related complications are a leading cause of maternal mortality, resulting in 15-30\% of maternal deaths in some studies.,9-14 To address the issue of unsafe abortions, the International Family Planning Fellowship Program (IFPFP) in advanced training in abortion and family planning was established in Ghana in 2008.

\section{CONTEXT}

Ghana is located in West Africa and has a population of about 25 million people, most of whom live in rural areas. The total fertility rate ranges from 3.1 in urban areas to 4.9 in rural areas. ${ }^{15}$ There are also large disparities across regions in access to health services, maternal mortality rates and rates of modern contraceptive use. According to the 2008 Ghana Demographic and Health Survey, more than $70 \%$ of Ghanaian women report that they either do not want any more children or would like to delay their next pregnancy. ${ }^{15}$ However, only about $16 \%$ of women report using a modern method of contraception. As a result, unplanned pregnancy and its consequences remain common in Ghana: Of all pregnancies in Ghana, 37\% are unplanned, including 23\% that are mistimed and 14\% that are unwanted. ${ }^{15}$

In 1985, Ghana passed a law permitting abortions performed by registered medical practitioners in instances in which the pregnancy is the result of rape, incest or "defilement of a female idiot"; if continuation of the pregnancy would risk the life of the woman or threaten her physical or mental health; or if there is substantial risk that the child would suffer from a serious physical abnormality or disease. ${ }^{16}$ Determining whether a woman meets one of these conditions appears to be largely up to the provider, and no special documentation is required for women to procure services.

The continued high rate of unsafe abortion in Ghana since the 1985 law is the result of multiple factors. Previous work suggests that inadequate knowledge about safe abortion services among patients and providers is a major contributor. ${ }^{6,7,17}$ Cost $^{18,19}$ privacy concerns and poor access to safe services (which tend to be centralized) 16,19,20 $^{2}$ have also been identified as reasons women-poor and rural woman in particular-seek services outside of the formal medical system. Public facilities are the usual sources of health care, including maternity care, for many women, but they often do not provide abortion services. ${ }^{21}$ Although abortion is legal in many circumstances, it continues to be stigmatized. Not only does this stigma discourage women from seeking services through the medical system, ${ }^{19}$ but it also deters health care providers from providing abortion services. ${ }^{20}$ In many settings, health care providers who offer abortion are marginalized and professionally isolated, making recruitment difficult.

Increasing the availability of family planning and safe abortion services is a key strategy to reduce unintended pregnancy and abortion rates, ${ }^{22}$ but this can be achieved only with a cadre of dedicated providers. Service providers, including obstetrician-gynecologists, have a crucial role to play in this effort. Although nonphysician clinicians make up a large portion of the family planning workforce in many countries, physicians with research and advocacy skills, as well as expertise in clinical medicine, are needed to ensure that governmental policies continue to support safe abortion access and availability. Specialized postgraduate training programs are one means of preparing innovative and effective leaders to engage in abortion and family planning policy and services. We hypothesized that such a training opportunity would encourage the development of family planning experts and abortion providers through its ability to legitimize the specialty, reduce provider isolation, add value to health care facilities and organizations, support professional growth and help sustain institutional support for providing safe abortions. Also, we hypothesized that as a result of these changes, such a training program would increase the quality of family planning and abortion education provided to other types of learners, such as medical students, nursing students and residents. This article describes our experiences in developing and implementing such a program in Ghana. 


\section{Program Context and Objectives}

Prior to 1989, medical school graduates seeking postgraduate training in obstetrics and gynecology had to leave Ghana to obtain training in the United Kingdom or Europe. Only 10\% returned to practice in Ghana, resulting in a massive "brain drain." In an effort to address the high rate of maternal mortality in Ghana, Ghanaian leaders, in consultation with the Royal College of Obstetricians and Gynaecologists, the American College of Obstetricians and Gynecologists, and the Carnegie Corporation, introduced a postgraduate residential training program in obstetrics and gynecology in 1989. ${ }^{23}$ This program was highly successful in building Ghana's health care provider base: As of 2006, 37 of 38 medical school graduates trained in the program remained in Ghana. ${ }^{24,25}$

Several individuals involved in starting the postgraduate residential training program have continued to develop programs to address maternal mortality and morbidity in Ghana over the past two decades. In the course of these efforts, the concept of a postgraduate training program in abortion and family planning was created. The objective was to train obstetrician-gynecologists for careers in advanced abortion techniques and family planning methods, and to create effective leaders who would train other clinicians, introduce new services, conduct research, advocate for policy change, and emerge as experts in abortion and family planning.

The fellowship's clinical training was intended to develop experts in complicated abortion and family planning services who would provide consultative services to generalists and midlevel clinicians. For instance, complicated cases might include technically difficult suction evacuation. In addition, the training might enable a physician to implement a new abortion service at a district hospital, which might require successfully convincing institutional leaders of its clinical necessity. Instead of simply being ready for independent practice, the fellows would be prepared to provide training to community members, students and professionals in a range of disciplines and settings. Being recognized as a clinical expert would help these individuals implement needed clinical service change at their organizations.

\section{Preparing for the Program}

- Faculty training. In preparation for the IFPFP, a threeweek seminar was conducted at the University of Michigan in late 2007 to develop a training team, to identify and define desired outcomes, to provide an update on contemporary clinical issues in abortion care and family planning, and to finalize the content of the curriculum. Participants were faculty in medicine and public health at the University of Ghana and Kwame Nkrumah University of Science and Technology (KNUST). These faculty were a mix of departmental leaders, physicians engaged in providing abortion and family planning services, and research faculty. The first week of the seminar provided detailed training on competency-based education methods, including pro- gram evaluation methods and performance-based clinical skills assessment. ${ }^{26,27}$ In week two, the team participated in leadership training exercises and team-based development of specific program goals. The final week consisted of presentations on contemporary aspects of clinical abortion and family planning services, including long-term contraceptive methods, postabortion/postpartum contraception and concepts in service implementation. In addition to the didactic training, the Ghanaian faculty developed the fellowship program's curriculum and a detailed outline for a textbook on abortion and family planning care in developing countries. The two-year curriculum was strongly grounded in competency-based medical education.

\section{Selection and Training of Fellows}

Fellowship positions were posted at the University of Ghana and KNUST, and applications were sought from across the country. The specific objectives and the measures used to assess the desired outcomes of the fellowship program are presented in Table 1. Upon completion of the program, graduates could apply for special certification in family planning and abortion care from the Ghana College of Physicians and Surgeons.

Applicants were interviewed, and four were selected by an advisory committee with representation from all sites. In July 2008, the four fellows began postgraduate training in family planning and abortion at the University of Ghana and KNUST. During the first month of the program, the fellows were each assigned at least one clinical and one research mentor to monitor their progress, conduct evaluations, and provide them with advice on career and leadership development. The training curriculum focused on three key educational competencies: clinical training in complicated abortion and contraceptive services, research methodology and leadership development.

- Clinical training. The program emphasized training in comprehensive abortion and postabortion care (such as medication abortion and the use of manual vacuum aspiration for incomplete and induced abortion) and longterm contraceptive methods (such as laparoscopic tubal ligation, vasectomy, IUDs and contraceptive implants). Clinical training was usually provided locally at government teaching hospitals affiliated with the participating medical schools and at several private, community-based

TABLE 1. Objectives and measured outcomes of the International Family Planning Fellowship Program in abortion and family planning

\begin{tabular}{|c|c|c|}
\hline Objective & Specific activities & Measured outcome \\
\hline Improve clinical skills & $\begin{array}{l}\text { Didactic training } \\
\text { Simulation training } \\
\text { Supervised procedures }\end{array}$ & $\begin{array}{l}\text { Case logs } \\
\text { Director evaluations } \\
\text { Self-evaluations }\end{array}$ \\
\hline $\begin{array}{l}\text { Improve skills in clinical } \\
\text { and health systems } \\
\text { research }\end{array}$ & $\begin{array}{l}\text { Didactic coursework } \\
\text { Contribute to ongoing research project } \\
\text { Mentored independent research project }\end{array}$ & $\begin{array}{l}\text { Coursework grade } \\
\text { Abstract presentations } \\
\text { Completed manuscript }\end{array}$ \\
\hline Improve leadership skills & $\begin{array}{l}\text { Leadership seminars } \\
\text { District placement } \\
\text { Work with local nongovernmental } \\
\text { organizations }\end{array}$ & $\begin{array}{l}\text { Seminar attendance } \\
\text { Log of nongovernmental or } \\
\text { community-based work }\end{array}$ \\
\hline
\end{tabular}


clinics. The training provided at private clinics not only increased the volume of cases the fellows handled, but also allowed them to learn about differing models of care and to enhance relationships between the various organizations providing contraception and abortion services in Ghana. When experienced Ghanaian faculty were not readily available, outside training opportunities were sought. For instance, we collaborated with other programs conducting simulation-based laparoscopic training sessions in Ghana. ${ }^{28}$

Upon completion of training, all fellows were deemed experts in clinical skills related to postabortion and comprehensive abortion care services up to 15 weeks' gestation, and to reversible long-term contraceptive methods. Fellows also demonstrated their competence in providing back-up for complicated abortion cases encountered by midwives, including early second-trimester cases, fibroids, and sepsis or other complications after unsafe abortion. None of the fellows achieved competence in laparoscopic tubal ligations, vasectomy or later second-trimester surgical abortions by the end of the program. Although all fellows participated in didactic and simulation-based training for basic laparoscopy, only one had completed live surgical cases by the end of the program. Barriers to achieving competency in laparoscopic surgery included low patient demand for interval sterilization and inconsistent availability of equipment, which resulted in too few cases to develop and maintain skills. After completing the training program, fellows continued to participate in laparoscopy training programs. Vasectomy training was also limited by low patient demand for services. We anticipate introducing training for graduated fellows and services at a later date, once the elements necessary for success, such as service demand, are in place.

Similarly, the program leadership concluded that much more empirical work was needed to better assess the need for second-trimester surgical abortion procedures in Ghana and the ideal implementation process. Given that current services already include induction termination, the value of adding second-trimester surgical abortion services is not clear. In addition, after consulting with experts with extensive experience in second-trimester surgical abortion in Africa, we felt that attempts to introduce second-trimester surgical abortion services would likely fail. An assessment of the feasibility of implementing such services is ongoing. - Research training. We recognized that attempts to introduce clinical service change often fail, particularly in the absence of empirical research in implementation strategies. Basic training in research methodology provides not only the skills needed to implement and evaluate the effects of clinical service change on women's health, but also provides skills valuable to quality assurance efforts, monitoring and funding applications. Coursework in epidemiology, biostatistics, health policy and research methodology was required. Didactic coursework, field placement and research mentorship was provided by Ghanaian faculty at each institution.
During the first year of the program, fellows spent about $75 \%$ of their time completing coursework, attending seminars in leadership training and gaining hands-on research experience by working on projects led by their mentors. During this year, fellows also developed independent research projects, which were subsequently the basis of the thesis required for certification. These independent projects were presented by the fellows at a family planning conference in the United States.

-Leadership development. Activities aimed at leadership development included a blend of seminars and fieldwork. Invited experts in Ghanaian law and policy conducted seminars for program faculty and fellows. Because we recognized the need to collaborate with the numerous existing organizations engaged in reducing maternal mortality in Ghana, ${ }^{2}$ fellows were required to provide service and education outside of the university setting. Several activities were used to meet this objective: a three-month placement with a district medical director, participation in leadership development seminars, and work with local nongovernmental organizations delivering safe abortion or family planning services. Work with local organizations included not only clinical service provision, but also participation in community education programs and outreach activities. Once fellows had been deemed competent by their clinical mentors, they engaged in more advanced activities, such as medical site quality evaluations. Last, to encourage their development as internationally recognized experts, each fellow was required to attend and make presentations at international family planning or reproductive health meetings. By the end of their fellowship training, all fellows had earned recognition as "family planning champions" by the Reducing Maternal Mortality and Morbidity in Ghana Program (http://www.r3m-ghana.org).

- Postgraduation follow-up. After program completion, all fellows obtained leadership positions at government hospitals. One, for example, heads the Department of Obstetrics and Gynecology at Tamale Teaching Hospital in the Northern Region, the poorest region in Ghana. All of the graduates are located at teaching hospitals and are engaged in training students, residents, family planning fellows and midlevel clinicians. Three of the four fellows passed their oral examinations and received certification through the Ghana College of Physicians and Surgeons in December 2011. The last fellow will complete his examinations in 2013. The program graduates also received two years of funding after graduation to support clinical service projects aimed at improving abortion and family planning services at their institutions. These projects focus on integrating contraceptive services into maternity care and abortion services, and implementing new postabortion and comprehensive abortion services in rural districts.

The clinical training aspect of IFPFP has now been taken over by the Reproductive Medicine and Family Planning Fellowship Program, run by the Ghana College of Physicians and Surgeons with funding by the Ministry of Health. The program, which enrolls 2-3 fellows each year, 
received seven applications for these positions in 2012. The first two fellows trained under the Ghana College program will complete their training in 2013. IFPFP continues to provide programmatic support and mentorship for these fellows, including access to funding for research and conference attendance. The Ghana College fellows regularly participate in ongoing IFPFP activities, including the annual program meeting in Ghana, collaborative roles on research projects and educational programs.

\section{CONCLUSION}

The IFPFP is the first subspecialty training program in comprehensive abortion care and family planning in West Africa. Access to safe abortion and contraceptive services is integral to efforts to decrease maternal mortality and to improve women's reproductive health worldwide. Providers dedicated to ensuring the availability of these services are crucial, but attracting and retaining them is often difficult. The existence of a subspecialty training program may alleviate enough of the deterrents to working in this field to build a network of physician leaders. Such a network would help ensure access to the abortion and family planning services needed to improve the health of Ghanaian women.

One of our first tasks was to design and implement a credible curriculum. To do so, we emphasized integrating effective assessment methods as a component of the curriculum and made daily, real-life activities the targeted educational outcomes. In particular, periodic direct observation by supervising faculty was integrated into the fellows' evaluation. These activities, specifically formulated for basic obstetrics-gynecology training, can range from care of uncomplicated pregnancies to surgical uterine evacuations after unsafe abortion. ${ }^{29}$ The activities identified for those undergoing fellowship training in family planning include not only providing clinical services such as highrisk or complicated abortion procedures, but also training other providers in abortion care, introducing new clinical services and advocacy work.

One of our key objectives was to develop physician leaders who would be effective at integrating abortion and family planning into training programs and clinical services, as well as serving as advocates and as consultants to policymakers through their research and testimony.

Over the course of the program, a number of lessons emerged. Perhaps the most important strength of this program was the longstanding relationship between the University of Michigan and the participating Ghanaian institutions. Several of the key leaders have worked together for more than a decade and have collaborated on a number of other successful programs in the area of medical education. These relationships were vital to our ability to anticipate challenges and negotiate solutions. Also, the governmental environment in Ghana, relative to that in other developing countries, was generally accepting of activities related to family planning and safe abortion. A number of agencies in both the public and the private sector were already engaged in reducing abortion-related mortality, and we attempted to connect with these groups whenever possible.

We deliberately designed this program to be administered through medical schools, in large part to foster the role that medical schools can have in building capacity around family planning services. In particular, we anticipated that the existence of such a program, by developing specially trained physicians in leadership positions, would enhance the family planning training of other learners, such as residents and medical or nursing students. Other work has shown that early exposure to abortion training during educational years is positively correlated with providing such services later. ${ }^{30}$ Although we find this approach valuable, it did come with a number of challenges. First, unlike many mission-driven nongovernmental organizations, medical schools have a huge range of responsibilities, priorities and views related to abortion and family planning. So, despite the strong support we received for the program from most institutions, turnover in various leadership positions required us to periodically "renegotiate" certain process elements of the program. Although this was time-consuming on occasion, we anticipate that as this specific training program continues and gains legitimacy, and new postgraduate training programs emerge, there will be fewer of these occasions.

The long-term goal of IFPFP is to decrease maternal mortality by decreasing the incidence of unplanned pregnancies and complications of unsafe abortion. We propose that this goal can be reached through a series of intermediate changes, beginning with the professional development of experts in abortion and family planning. The existence of a subspecialty in abortion and family planning highlights the value of the field and will create a community of dedicated physicians. While initially the impact of these individuals will be realized locally, as their work is disseminated, we believe that they will be recognized as invaluable resources for other areas in Ghana. As the network of experts grows and its members are integrated into educational, research and policy settings, safe abortion and family planning activities will remain in the forefront of maternal mortality prevention efforts.

The IFPFP focuses on one of several strategies that are needed to reduce maternal mortality in Ghana-supporting the emergence of dedicated physicians who will be involved in the complete range of activities needed to prevent unsafe abortion. Achieving significant improvement in maternal mortality will require continued commitment from partners for many years. Although the program would need to be tailored to the specific context, this postgraduate training program could serve as a model and resource for other countries in their efforts to improve women's health.

\section{REFERENCES}

1. Mbizvo MT and Say L, Global progress and potentially effective policy responses to reduce maternal mortality, International Journal of Gynaecology \& Obstetrics, 2012, 119(Suppl. 1):S9-S12.

2. World Health Organization, (WHO), Unsafe Abortion: Global and 
Regional Estimates of the Incidence of Unsafe Abortion and Associated Mortality, sixth ed., Geneva: WHO, 2011, <http://www.who.int/ reproductivehealth/publications/unsafe_abortion/9789241501118/ en/>, accessed Jan. 15, 2012.

3. Ahman E and Shah $\mathrm{IH}$, New estimates and trends regarding unsafe abortion mortality, International Journal of Gynaecology $\&$ Obstetrics, 2011, 115(2):121-126

4. Berer M, Making abortions safe: a matter of good public health policy and practice, Bulletin of the World Health Organization, 2000, 78(5):580-592.

5. Baiden F et al., Unmet need for essential obstetric services in a rura district in northern Ghana: Complications of unsafe abortions remain a major cause of mortality, Public Health, 2006, 120(5):421-426.

6. Morhe ES, Morhe RA and Danso KA, Attitudes of doctors toward establishing safe abortion units in Ghana, International Journal of Gynaecology \& Obstetrics, 2007, 98(1):70-74.

7. Konney TO et al., Attitude of women with abortion-related complications toward provision of safe abortion services in Ghana, Journal of Women's Health, 2009, 18(11):1863-1866

8. Ahiadeke C, Incidence of induced abortion in southern Ghana, International Family Planning Perspectives, 2001, 27(2):96-101 \& 108.

9. Geelhoed DW et al., Trends in maternal mortality: a 13-year hospitalbased study in rural Ghana, European Journal of Obstetrics, Gynecology, and Reproductive Biology, 2003, 107(2):135-139.

10. Gumanga SK et al., Trends in maternal mortality in Tamale Teaching Hospital, Ghana, Ghana Medical Journal, 2011, 45(3):105-110.

11. Ganyaglo GY and Hill WC, A 6-year (2004-2009) review of maternal mortality at the Eastern Regional Hospital, Koforidua, Ghana, Seminars in Perinatology, 2012, 36(1):79-83.

12. Mills $S$ et al., Maternal mortality decline in the Kassena-Nankana district of northern Ghana, Maternal and Child Health Journal, 2008, 12(5):577-585.

13. Zakariah AY et al., Reproductive age mortality survey (RAMOS) in Accra, Ghana, Reproductive Health, 2009, 6(6):7.

14. Asamoah BO et al., Distribution of causes of maternal mortality among different socio-demographic groups in Ghana; a descriptive study, BMC Public Health, 2011, 11:159

15. Ghana Statistical Service and Macro International, Ghana Demographic and Health Survey 2008, Preliminary Report, Accra, Ghana: Ghana Statistical Service; and Calverton, MD, USA: Macro International, <http://pdf.usaid.gov/pdf_docs/PNADO176.pdf>, accessed Jan. 17, 2012.

16. Morhee R and Morhee E, Overview of the law and availability of abortion services in Ghana, Ghana Medical Journal, 2006, 40(3):80-86.

17. Voetagbe $G$ et al., Midwifery tutors' capacity and willingness to teach contraception, post-abortion care and legal pregnancy termination in Ghana, Human Resources for Health, 2010, 8:2.

18. Afenyadu D and Goparaju L, Adolescent Sexual and Reproductive Health Behavior in Dodowa, Ghana, Washington, DC: Centre for Development and Population Activities, 2003, <http://www.cedpa. org/content/publication/detail/660.html>, accessed July 5, 2012

19. Hill ZE, Tawiah-Agyemang $C$ and Kirkwood B, The context of informal abortions in rural Ghana, Journal of Women's Health, 2009, 18(12):2017-2022

20. Baiden F, Making safe abortion services accessible in Ghana, Journal of Women's Health, 2009, 18(12):1923-1924

21. Aboagye PK et al., An Assessment of the Readiness to Offer Contraceptives and Comprehensive Abortion Care in the Greater Accra, Eastern and Ashanti Regions of Ghana, Chapel Hill, NC, USA: Ipas, 2007, <http://www.ipas.org/ /media/Files/Ipas\%20Publications/ LAPMGHAE07.ashx>, accessed July 5, 2012

22. Tsui AO, McDonald-Mosley R and Burke AE, Family planning and the burden of unintended pregnancies, Epidemiologic Reviews, 2010, 32(1):152-174.

23. Klufio CA et al., Ghana postgraduate obstetrics/gynecology collab- orative residency training program: success story and model for Africa, American Journal of Obstetrics E Gynecology, 2003, 189(3):692-696.

24. Anderson FW et al., Who will be there when women deliver? Assuring retention of obstetric providers, Obstetrics \& Gynecology, 2007, 110(5):1012-1016

25. Clinton Y, Anderson FW and Kwawukume EY, Factors related to retention of postgraduate trainees in obstetrics-gynecology at the Korle-Bu Teaching Hospital in Ghana, Academic Medicine, 2010, 85(10):1564-1570.

26. Holmboe ES, Hawkins RE and Huot SJ, Effects of training in direct observation of medical residents' clinical competence: a randomized trial, Annals of Internal Medicine, 2004, 140(11):874-881.

27. Norcini JJ, Work based assessment, BMJ, 2003, 326(7392):753755.

28. Gamble $C$ et al., A low-cost laparoscopic surgical training program for resource limited settings: a pilot study, unpublished report, Ann Arbor, MI, USA: Center for Global Health, University of Michigan, 2011

29. ten Cate $O$ and Scheele F, Competency-based postgraduate train ing: Can we bridge the gap between theory and clinical practice? Academic Medicine, 2007, 82(6):542-547.

30. Steinauer J et al., Predictors of abortion provision among practicing obstetrician-gynecologists: a national survey, American Journal of Obstetrics \& Gynecology, 2008, 198(1):39.el-39.e6

\section{Acknowledgments}

The authors are grateful to an anonymous donor for support of this program. They also extend thanks to the directors and mentors for their dedication to the fellows and the program (Drs. Frank Ankobea-Kokroe, Richard Adanu, Agathe Bonney, Harry Tagbor, Baafour Opoku, Gerald Owusu-Asubonteng, Kwasi Apea-Kubi, Rexfore Kofi Asante, Gloria Quansah Asare, Samuel Obed, Ali Samba, Jason Bell, Lisa Harris and Willie Parker).

Author contact:daltonvk@med.umich.edu

\section{Correction}

In "Incidence of Induced Abortion by Age and State, Mexico, 2009: New Estimates Using a Modified Methodology," by Fatima Juarez and Susheela Singh [2012, 38(2):58-67], the last sentence on page 62 should read: "By comparison, less variation was evident among the seven states in Region 3, where the abortion rate generally ranged from 33 (in Sinaloa) to 44 (in Durango); ...." The last sentence before the Discussion section (page 63) should read: "This is not surprising, given that the states in this region have higher fertility levels than those in other regions." 